
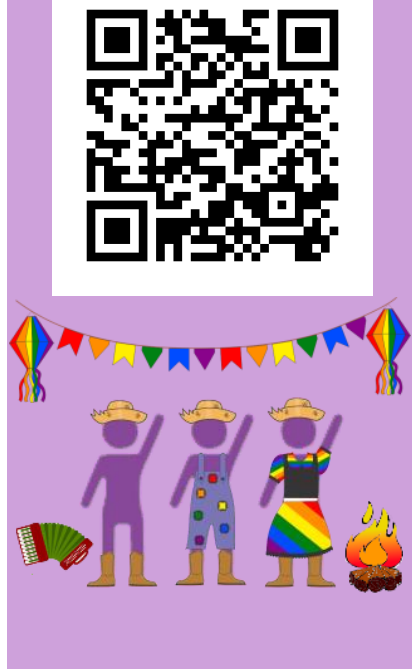

\title{
Possibilidades às Pedagogias Decoloniais a Partir de Práticas Educativas com Crianças Ribeirinhas na Amazônia
}

Alder de Sousa DIAS, Universidade Federal do Amapá

Waldir Ferreira de ABREU, Universidade Federal do Pará

Resumo: O presente artigo, ao tematizar as pedagogias decoloniais, traz como especificidade as práticas pedagógicas com crianças, realizadas no contexto amazônida e ribeirinho. Tem a seguinte questão-problema: que contribuições às pedagogias decoloniais podem advir de práticas pedagógicas com crianças ribeirinhas na Amazônia? Nesse sentido, objetiva análisar possíveis contribuições de práticas pedagógicas com crianças ribeirinhas na Amazônia às pedagogias decoloniais. Metodologicamente, trata-se de uma pesquisa bibliográfica, de abordagem qualitativa, ancorada em alguns referenciais, como Coelho (2020), Mota Neto (2016), Dussel (1980; 1994; 2017; 2020), Mignolo (2008; 2014), entre outros, e que contou com elementos da análise do conteúdo como técnica de sistematização e análise de dados. Entre os resultados e conclusões, tem-se que as pedagogias decoloniais, como pujança intelectual, ainda não estão organicamente assumidas pelo professorado em geral, mas como energia de descontentamento, fazem-se presentes a operar fraturas epistêmicas à pedagogia moderno-colonial.

Palavras-Chave: Pedagogias decoloniais. Práticas pedagógicas. Criança ribeirinha. Amazônia. 


\section{Introdução}

O presente artigo tematiza as pedagogias decoloniais, tendo-se por recorte específico a prática educativa com crianças da Amazônia ribeirinha. Tem por objetivo realizar uma análise de possíveis contribuições de práticas pedagógicas com crianças ribeirinhas na Amazônia às pedagogias decoloniais.

Resulta da intersecção entre duas pesquisas vinculadas ao Programa de Pós-Graduação em Educação do Instituto de Ciências da Educação da Universidade Federal do Pará. A primeira delas, resultante de uma pesquisa de campo, etnográfica, deu origem à dissertação de mestrado: "Práticas pedagógicas de professores do multisseriado na tríplice fronteira Amazônica Brasil-Peru-Colômbia: um olhar decolonial na educação ribeirinha", defendida no ano de 2020 e que analisou, a partir do referencial da decolonialidade, se as práticas pedagógicas de professores do multisseriado consideram a identidade cultural de crianças ribeirinhas na tríplice fronteira amazônica Brasil-Peru-Colômbia (COELHO, 2020).

A segunda pesquisa: "Educação Popular e Pensamento Decolonial Latino-Americano em Paulo Freire e Orlando Fals Borda", defendida em 2015, trata-se de tese uma doutoral, que metodologicamente se estruturou sob a forma de pesquisa teórica e que teve como objetivo a análise da constituição de uma concepção decolonial no pensamento social e pedagógico de Paulo Freire e de Orlando Fals Borda, identificando aportes para uma pedagogia decolonial, desde a ancoragem da educação popular latinoamericana (MOTA NETO, 2015). No ano seguinte, esta tese foi publicada em forma do livro, com o título: "Por uma Pedagogia Decolonial na América Latina: reflexões em torno do pensamento de Paulo Freire e Orlando Fals Borda”. É a partir desta obra que dialogaremos no presente artigo.

Da dissertação de Coelho (2020), realizamos uma análise de seu dados de campo, mas em diálogo com alguns referenciais teóricos decoloniais não abordados pela autora, dando maior ênfase nos indicativos às pedagogias decoloniais propostos por Mota Neto (2016). De modo que lançamos mão da seguinte questão-problema a nos orientar: que contribuições às pedagogias decoloniais podem advir de práticas pedagógicas com crianças ribeirinhas na Amazônia? 
Trata-se de uma pesquisa bibliográfica, de abordagem qualitativa, ancorada em alguns referenciais, como Coelho (2020), Mota Neto (2016), Dussel (1980; 1994; 2017; 2020), Mignolo (2008; 2014), entre outros, e que contou com elementos da análise do conteúdo como técnica de sistematização e análise de dados.

Em linhas gerais, além desta Introdução, e, consequentemente das Considerações finais, o texto está estruturado em outras três partes a abordar o detalhamento metodológico da pesquisa que originou o presente artigo, o referencial teórico adotado, com foco para uma compreensão do que sejam as pedagogias decolonais, e, de uma análise das práticas pedagógicas registradas por Coelho (2020) em diálogo com os indicadores de Mota Neto (2016).

\section{Caminho Metodológico}

A pesquisa da qual resulta o presente artigo adotou a abordagem qualitativa, na medida em que trabalhou com um universo de dados categoriais que permitem diversas interpretações, cuja quantificação não cabe como referência metodológica predominante (MINAYO, 2015), mais precisamente, com o conjunto de dados registrados por Coelho (2020), durante sua pesquisa etnográfica.

Analisamos a dissertação de Coelho (2020), tendo-se como base elementos da análise de conteúdo. No caso, considerando que categorias analíticas são: "[...] conceitos retirados do referencial teórico utilizado na pesquisa, que possibilitam a análise e interpretação dos dados" (OLIVEIRA; MOTA NETO, 2011, p. 164), adotou-se as categorias analíticas principais: colonialidade/modernidade (MIGNOLO, 2008); pensamento decolonial (MIGNOLO, 2008); transmodernidade (DUSSEL, 2017); e pedagogias decoloniais (WALSH, 2009; PALERMO, 2014; MOTA NETO, 2016).

Para fins de classificação e análise dos dados, foi preciso fazer uso de categorias temáticas, que são indicadores de análise e podem ser: "fatores, aspectos, elementos do fato ou situação em estudo, que são classificados e reunidos em eixos ou unidades temáticas a partir e com os dados coletados" (OLIVEIRA; MOTA NETO 2011, p. 164).

Nesse sentido, procedeu-se com a análise temática dos dados de campo a partir de cinco referenciais das pedagogias decoloniais: (1) a necessidade de educadores subversivos; (2) partir de uma hipótese de 
contexto; (3) valorizar memórias coletivas dos movimentos de resistência; (4) buscar "outras" coordenadas epistemológicas; e (5) afirmar-se como uma utopia política (MOTA NETO, 2016).

\section{Pedagogais Decoloniais: Bases Teóricas}

Não é possível falar de pedagogias decoloniais sem abordar anteriormente a modernidade/colonialidade/decolonialidade, que surgem como hidra de três cabeças - reforçando a metáfora de Mignolo (2008) e tendo como marco histórico de sua origem a conquista das Américas, datada a partir do ano de 1492 (DUSSEL, 1994).

Em outras palavras, a partir deste marco histórico, a Europa central passa a se colocar, pela primeira vez, como "epicentro" geopolítico do sistema-mundo, impondo não apenas o colonialismo como meio de dominação infra e supra estrutural, mas passando a desenvolver também a colonialidade/modernidade como imposição do modus vivendi europeu, no sentido exploratório e ideológico desde um mito desenvolvimentista, em que o homem, europeu, coloca-se como o moderno e o civilizado, ante o modus vivendi bárbaro, sub-humano, inferior dos povos originários, e por isso, marginalizados (DUSSEL, 1994).

Desde esses marcos históricos, o pensamento decolonial assume sua primeira forma, isto é, como energia de descontentamento (MIGNOLO, 2008) em relação à modernidade/colonialidade operada aos povos oprimidos, subalternizados e invisibilizados pela então expansão geopolítica europeia e as consequências dela decorrentes.

Diferentemente de sua primeira face (energia de descontentamento) que surge no final do século XV (1492), do ponto de vista intelectual, o pensamento decolonial é muito mais recente e remonta cinco gerações, todas situadas a partir do século XX (DUSSEL, 2020).

Intelectualmente, concordamos que o pensamento decolonial ou decolonialidade - remonta, originalmente, aos anos 1960, e a distintos intelectuais e ativistas de diversos lugares do mundo, tal como destaca Mignolo (2014, p. 28, tradução nossa):

A decolonialidade foi claramente formulada nos anos sessenta e setenta por pensadores árabe-islâmicos (Sayyid Qutb, Ali Shariati, Aiatolá Komeini); por pensadores afro-caribenhos (Aimé Césaire, Frantz Fanon) pela Filosofia da Libertação na América Latina e por intelectuais e ativistas indígenas na América Latina, Austrália, Nova Zelândia e Canadá. 
Essa dualidade entre energia de descontentamento e pujança intelecutal permite uma melhor compreensão do pensamento decolonial, não apenas como prática, nem tampouco como teoria, mas como práxis, e práxis decolonial, quer quiser: luta, resistência e produção científicointelectual engajada em favor da construção de um mundo em que as alteridades são respeitadas e devidamente dignificadas como o que são, expressões do gênero humano.

Nesse sentido, é pertinente considerar que, conforme Mignolo (2014), a decolonialidade é um processo para se chegar à transmodernidade, sendo esta a utopia de um modo "outro" de existir, de uma nova idade da civilização planetária e pluriversal (DUSSEL, 2017).

Desde a utopia transmoderna, compreendemos que o pensamento decolonial se desdobra em muitas frentes de luta como a do Movimento dos Sem Terra e a luta por uma educação do campo, por exemplo, haja vista que não se limita a sujeitos, incorpora movimentos sociais e instituições (MIGNOLO, 2008).

É desde essa ancoragem que se pode falar em pedagogias decoloniais, que nos dizeres de Walsh (2009 p. 27), são:

[...] pedagogias que dialogam com os antecedentes crítico-políticos, ao mesmo tempo em que partem das lutas e práxis de orientação decolonial. Pedagogias que [...] enfrentam o mito racista que inaugura a modernidade [...] e o monólogo da razão ocidental; pedagogias que se esforcem por transgredir, deslocar e incidir na negação ontológica, epistêmica e cosmogônica-espiritual que foi, e é, estratégia, fim e resultado do poder da colonialidade.

Nesse sentido, são muitos os sujeitos que se engajam em projetos "outros" de sociedade e de processos educativos, em distintas situações, que se colocam contra a pedagogia moderno-colonial e que propõem pedagogias críticas alinhadas ao projeto decolonial, evidenciando suas especificidades, sem perder de vista o diálogo com o todo. Nesse sentido, corrobora Palermo (2014, p. 139, tradução nossa):

Estas situações dialógicas tornadas ato por distintos agentes, de distintas pertinências no espaço educativo e disciplinar tornaram visíveis, ao mesmo tempo, os problemas específicos e as expectativas gerais em direção a uma ordem transformadora de saber. Uma ordem nascida do diálogo, que evite a reprodução do pensamento único desprendido das relações de poder definitivamente vigentes na pedagogia do controle e da autoridade, na 'pedagogia da crueldade'. 
Para além das perspectivas andina (Catherine Walsh) e argentina (Zulma Palermo), tem-se a obra brasileira de Mota Neto (2016), que também expressa uma definição de pedagogia decolonial ancorada nos antecedentes críticos de Paulo Freire e Orlando Fals Borda e que aponta para a práxis da luta contra a colonialidade/“modernidade", que se dá por meio de processos de formação humana, tendo em vista a construção de uma sociedade justa, solidária, livre e amorosa, surgindo dos movimentos sociais. A esse respeito, assim se refere:

[...] a pedagogia decolonial refere-se às teorias-práticas de formação humana que capacitam os grupos subalternos para a luta contra a lógica opressiva da modernidade/colonialidade, tendo como horizonte a formação de um ser humano e de uma sociedade livres, amorosos, justos e solidários. (MOTA NETO, 2016, p. 318)

Concordamos com estas perspectivas conceituais, pois delineam a práxis contra a colonialidade/modernidade, desde o campo educacional, como fator de unidade, mas acrescentamos nosso posicionamento: as pedagogias decoloniais são pedagogias que objetivam processos educativos "outros", isto é, que considerem positivamente a alteridade e a pluriversalidade que marca o gênero humano em todos os quadrantes do planeta, nos seus distintos modus vivendi, valorizando o "sul" geopolítico e cultural, mas em diálogo crítico de subsunção com o "norte”, em vista da utopia transmoderna.

Por esse motivo, faz-se muito mais pertinente o uso do termo no plural: pedagogias decoloniais, do que seu uso no singular, haja vista que os sujeitos e os contextos são pluriversos por natureza. Ideia reforçada por Arroyo (2014) ao defender que para outros sujeitos, é preciso outras pedagogias.

Mota Neto (2016), contribui com algumas indicações práticas para se fazer pedagogias decoloniais, sem, obviamente, esgotar o assunto. São elas:

1. Pedagogias que requer educadores subversivos: Educadores e educadores decoloniais não podem apenas reproduzir o modus vivendi do paradigma moderno-colonial, por mais aparentemente que isso pareça. Pelo contrário, educadoras e educadores devem ter consciência e práxis subversiva no sentido de lutar e atuar em vista de uma sociedade outra, de modo a contribuir com a conscientização dos sujeitos do processo educativo em questão, combinando, em sua inteireza, visão de mundo e práxis. 
2. Pedagogias que partem de uma hipótese de contexto: É fazer com que a prática educativa esteja diretamente ligada às realidades de vida do grupo em questão, sem desconsiderar questões micro ou macro sociais. Indicativo pedagógico que pressupõe o estabelecimento da alteridade com o saber local de modo geral, a favorecer o diálogo de saberes e a síntese cultural, dando visibilidade a quem antes era invisibilizado.

3. Pedagogias que valorizam as memórias coletivas dos movimentos de resistência: trata-se da valorização das memórias coletivas, que apesar da violência da colonialidade/modernidade, são base de conhecimentos e estratégias de sobrevivência e enfrentamento decolonial.

4. Pedagogia em busca de outras coordenadas epistemológicas: trata-se de pensar e agir desde uma educação que parta de outros referenciais para além do moderno-colonial, sem evidentemente, deixar de lado - de modo fundamentalista positividades da produção cultural do norte global.

5. Pedagogias que se afirmam como utopia política: nesse sentido, educadoras e educadores têm a direção da luta, da proposição, e não apenas da crítica e da denúncia, deixando claro a politicidade da educação e a educabilidade da política, tendo em vista um mundo solidário, democrático $\mathrm{e}$ participativo.

Esses são alguns indicativos para práticas pedagógicas em perspectiva decolonial, apontados por Mota Neto (2016), que se baseiam nos legados de Paulo Freire e de Orlando Fals Borda, desde os marcos da educação popular latinoamericana. Mais adiante, estes mesmos referenciais serão colocados em diálogo com os achados de Coelho (2020).

\section{Uma Análise Decolonial de Práticas Pedagógicas com Crianças Ribeirinhas: Indicativos às Pedagogias Decoloniais}

Essa seção inicia com uma descrição do cotidiano de vida das crianças que frequentam a escola locus de estudo. Em seguida, realizamos uma caracterização geral de seu ambiente de aprendizagem escolar, para, por fim, evidenciarmos algumas indicações práticas de como se fazer 
pedagogias decoloniais, considerando-se, além do referencial teórico adotado, as apreensões obtidas durante as observações, as entrevistas e as anotações de campo de Coelho (2020).

\section{Caracterização Existencial das Crianças Riberinhas}

Não é possível observar as crianças, fora do seu ambiente natural, isto é, com suas interações interpessoais com adultos e outras crianças e com a natureza. Nesse sentido, em vez de negar ou invisibilizar, optamos por dar ênfase à realidade social das crianças que protagonizaram a pesquisa de Coelho (2020).

Nesse caso, notamos, desde o ponto de vista de Coelho (2020), o quanto as águas servem para navegação às comunidades, para a praia, a roça, a densa floresta, os igapós, e para acesso à sede do município. Das águas amazônicas - rio, igapós e lagos - as famílias pescam o alimento diário, captam água para as atividades cotidianas, como lavar louça, lavar roupa, limpar a casa e cuidar dos animais domésticos e domesticados.

Nessa dinâmica, as águas também dinamizam a vida social das crianças, pois estabelecem contato direto com a natureza no seu fazerbrincar. Por exemplo, as águas permitem que as crianças criem e recriem modos de brincar, como "pega-pega", prender a respiração por mais tempo, enfim, brincadeiras que conduzem a diversão, mas também são modos de se constituírem sujeitos amazônidas, habitantes de comunidades ribeirinhas (COELHO, 2020).

Desse modo, as crianças desse contexto ribeirinho vão se tornando membros da espécie humana (hominização), constroem relações sociais de existência (humanização) e se tornam seres humanos singulares (singularização) (CHARLOT, 2000).

Esse processo de hominização, humanização e singularização envolve uma multiplicidade de elementos sobre as quais as crianças desenvolvem suas relações socioespaciais (OLIVEIRA NETO; SOBREIRO FILHO, 2017), que ajudam na constituição das crianças amazônidas ribeirinhas: sua casa, o espaço vivido, concebido e sentido nas suas relações mediadas pelo rio, terra e floresta.

Nessa direção, Coelho (2020) destaca que as casas das crianças são margeadas pelas águas (na enchente) e pelas terras (na vazante) por 
estarem em terras de várzea. Como essa realidade marca suas vidas, elas aprendem a nadar desde cedo, a conhecer as temporalidades, os perigos e os cuidados que devem ter, a importância para sua existência.

Nesse sentido, percebemos que as crianças são conhecedoras desse espaço e dos significados e sentido para sua vida. Conhecimento de vida, de existência que se dá intersubjetivamente, entre elas mesmas e relação com os adultos.

Desse modo, vão à escola não como "tábulas rasas", mas com grande saber de experiência feito, no sentido freiriano, isto é, como saber do educando gerado pelo contexto concreto da cotidianidade (FREIRE, 1997).

Veja-se, por exemplo, o um trecho do relato de Educando 1: "Eu gosto de fazer casa. Eu ajudo meu avô. Eu e meu avô nós derruba a casa e faz outra casa nova. Eu carrego tábua e martelo com prego. Ah! Eu carrego listão e ferro. Eu tenho dois quartos" (COELHO, 2020, p. 153). Saberes esses que se originam de experiências com os adultos, mas segue adiante por meio da comunicação entre outros sujeitos de distintas faixas intergeracionais, chegando, inclusive, ao espaço próprio da educação escolar.

\section{Uma Caracterização Geral do Ambiente de Aprendizagem das Crianças}

Durante a estada na comunidade e a observação da dinâmica escolar feita por Coelho (2020), percebemos uma rotina pedagógica junto à turma multisserial, conforme descrita a seguir. As aulas iniciavam geralmente às $07 \mathrm{~h} 30$, após todos se organizarem no espaço da escola e a professora resolver outras demadas, como a merenda escolar. Em seguida, na sala de aula, a professora direcionava as atividades para os alunos, conforme sua etapa formativa: educação infantil (pré-I e pré-II) e ensino fundamental ( $1^{\circ}$ e $2^{\circ}$ anos).

Havia o intervalo para o recreio, momento no qual as crianças merendavam e brincavam. No período da enchente, brincavam no pátio da escola. Na seca, brincavam no entorno da escola. No retorno desse intervalo, continuavam os exercícios propostos: normalmente, leituras com a professora ou ainda brincavam com os poucos brinquedos dispoíveis. As $11 \mathrm{~h}$ retornavam para suas casas. 
Para as crianças do pré I e pré II, sua prática perpassava pelos desenhos livres, atividades de coordenação motora e repetição de vogais e números de o a 9. Também era comum pedir às crianças que cantassem alguma música ou que fizessem desenhos livres.

Havia uma preocupação da professora de que as crianças logo desenvolvessem a habilidade de escrever. Para tanto, escrevia no caderno as vogais ou letras do alfabeto para que as crianças fossem desenvolvendo tal habilidade.

No que se refere às crianças dos anos iniciais de $1^{\circ}$ e $2^{\circ}$ anos, que dividem a mesma sala da educação infantil, as práticas pedagógicas eram mais pontuais, como: atividades de cópias do quadro branco e leitura do alfabeto e sílabas, principalmente pequenos textos, que tratam na maioria das vezes, de assuntos distantes da realidade social das crianças ou pouco articulados com esta realidade.

A prática pedagógica se pautava no processo de ensino da leitura e da escrita, sem distinção de série e idade. Como relata a Professora: "Eu, como professora, vejo que deixo de lado os pequenos [...] pra dar atenção lá pros menino do $1^{\circ}$ e $2^{\circ}$, pra aprender ler, escrever [...]" (COELHO, 2020, p. 172).

Então, a preocupação da professora tem se primado pela alfabetização das crianças dos anos inciais. E, as cópias que retirava do seu livro didático foram as práticas mais adotadas para trabalhar isso, dando ênfase nas disciplinas Língua Portuguesa e Matemática, com foco para conteúdos do alfabeto e sílabas simples, números e cálculos elementares de adição (COELHO, 2020).

Para ter acesso à alfabetização, a professora somente contava com o livro didático e os alunos, com o caderno. Na sala de aula não haviam cartazes ilustrativos que direcionassem e nem livros didáticos para pequisa e recorte. Além disso, as crianças têm dificuldades nas cópias do quadro branco. Demoram repassar para o caderno e sentem dificuldades em responder os exercícios, em especial, os de interpretação.

Além desse aspecto, o acompanhamento familiar nas atividades escolares pode ser um fator que implica nas dificuldades de aprendizagem. No decorrer da pesquisa a falta de acompanhamento dos pais ficava evidente, sobretudo quando as crianças traziam as atividades sem serem feitas em casa. 
Em conversa com os pais, Coelho (2020) constatou que a maioria, não todos, não tem domínio da leitura e escrita, sendo que quem acompanha as crianças nas atividades, na maioria das vezes, é o irmão, que em geral está mais adiantado nos estudos escolares. Mas também, há pais que conseguem acompanhar as atividades, porém não compreendem o contexto da atividade. Assim, em linhas gerais, a aprendizagem das crianças tende a ficar centrada no trabalho pedagógico da professora, restrito ao horário escolar, isto é, das 7h30 às 11h.

\section{Indicativos às Pedagogias Decoloniais Desde a Realidade De Crianças Ribeirinhas}

Na sequência, socializamos uma análise feita a partir de algumas correlações entre as registros de campo de Coelho (2020) e os indicativos às pedagogias decoloniais, propostos por Mota Neto (2016), explicitados anteriormente, quais sejam: (1) a necessidade de educadores subversivos; (2) partir de uma hipótese de contexto; (3) valorizar memórias coletivas dos movimentos de resistência; (4) buscar "outras" coordenadas epistemológicas; e (5) afirmar-se como uma utopia política.

\section{1 - A Necessidade de Educadores Subversivos}

Tanto Walsh (2009), quanto Palermo (2014) e Mota Neto (2016) apontam para atividades pedagógicas conscientes em relação a uma opção ético-política em vista de operar fraturas no paradigma moderno-colonial, tendo por meio as pedagogias decoloniais. Contudo, partimos da hipótese de que esse discurso - como pujança intelectual decolonial - ainda não se efetiva na prática da grande maioria do professorado brasileiro, seja porque essa discussão passou a se fazer presente a pouco tempo na produção stricto sensu nacional ou mesmo porque ainda falta tal temática andentrar no campo da formação de professores.

Por exemplo, em relação ao primeiro aspecto da hipótese, evidenciamos que apenas no ano de 2010, temos a tese de Luiz Fernandes de Oliveira como a primeira a se apropriar do pensamento decolonial visando a (re)construção de paradigmas "outros" em relação à educação étnico-racial (DIAS; ABREU, 2020). Nesse sentido, o próprio autor aponta o distanciamento concreto para se chegar a desenvolver uma pedagogia propriamente decolonial, dentro do campo temático pesquisado (OLIVEIRA, 2010). 
E, no que ser refere à presença do pensamento decolonial na formação de professores, Walsh, Oliveira e Candau (2018), apontam que tem aumentado a aderência de pesquisadoras e pesquisadores no sentido de formular uma educação "outra", desde os sujeitos subalternizados pela colonialidade.

Mais especificamente, Legramandi e Gomes (2019) apontam que a formação do professorado em exercício seja revista por meio de suas relações com a comunidade escolar em que atua, levando-se em conta práticas emancipatórias, politicamente comprometidas e de base intercultural, ao mesmo tempo em que reconhecem a lentidão da apropriação da práxis decolonial, visando o desprendimento de princípios e práticas do paradigma moderno-colonial.

Ainda nesse direção, Aood, Dias e Abreu (2021), recentemente, apontam para um direcionamento de trabalho investigativo voltado para o campo da formação docente, a envolver: demarcação de princípios éticopolíticos e epistemológicos e algumas frentes de pesquisa, como investimento de esforços em epistemologias e metodologias que dialoguem materialmente com a base popular e a necessidade de se "mapear" as produções científicas acerca de pedagogias decoloniais.

Embora a professora não tenha consciência teórica sobre o trabalho pedagógico com as pedagogias decoloniais, não significa dizer que, em sua prática não estejam presentes indicativos de subversão à pedagogia moderno-colonial, no sentido de uma energia de descontentamento (MIGNOLO, 2008).

Observe-se por exemplo, que diante do contexto de marginalização educacional em que se encontra: não conta com livros didáticos para as crianças, não conta com materiais de apoio pedagógico, como cartolina, pinceis e brinquedos, a professora se desdobra para realizar práticas educativas melhor contextualizadas,como pudemos observar na Semana da Criança, onde, apesar da invisibilidade educacional da escola para com o sistema municipal, ela retirou dinheiro do próprio bolso para a aquisição de materiais de apoio e assim realizar a ação proposta e realizou brincadeiras e dinâmicas tendo a intenção de fortalecer a identidade cultural das crianças, como será visto mais adiante.

Isso não significa que a professora não tenha senso crítico, ou que tenha assimilado a ideologia do voluntariado neoliberal, que deflaciona o papel social do Estado. Por exemplo, ao indagarmos sobre suas principais dificuldades, assim se expressou: 
Acho que é o apoio da comunidade [...] a comunidade é ausente, falta a parceria da comunidade, porque a escola é da comunidade. Tem eventos da comunidade, por exemplo, o santo padroeiro, uma festa religiosa de São Pedro, não há parceria, não nos convidam, não vem à escola falar sobre o assunto. Vejo nas outras comunidades que cada festa, Festa do maracujá, Festa da melancia, festa dos padroeiros, a escola é convidada e participa, os alunos participam, mas na comunidade Boa Vista não. [...]. Mas acho também que muitos da comunidade não participam porque os alunos da comunidade são minoria, são 4 ou 5 alunos que são da comunidade mesmo. [...] (Entrevista com Professora) (COELHO, 2020, p. 166).

Assim, ter professoras e professores subversivos é um indicativo assertivo e fundamental, mas, conforme os condicionantes explicitados anteriormente, requer uma processualidade lenta, que demanda investimento praxiológico em vista de que o discurso anunciativo das pedagogias decoloniais se torne orgânico na prática docente, a ser assumido como indentidade profissional, ao ponto de uma professora anunciar claramente: "me filio às pedagogias decolonais", da mesma forma que outra diria: "sou da pedagogia histórico-crítica" ou "a pedagogia freiriana me é mais pertinente”. Realidade esta, distante de se alcançada no caso em tela.

\section{2 - Partir de uma Hipótese de Contexto}

Tal como explicita Mota Neto (2016), este é o indicativo que melhor traduz para a prática pedagógica a inclusão decolonial dos modus vivendi dos sujeitos do processo ensino-aprendizagem, que ética e politicamente envolvem opção da educadora ou do educador, que reconhece as alteridades negadas e os saberes invisibilizados destes.

Ante essa perspectiva, percebemos já na caracterização existencial das crianças riberinhas, feita em linhas anteriores, há uma imensa quantidade de saberes que podem ser contextualizados como os saberes de sala de aula. Referimo-nos objetivamente aos seus saberes sobre as águas, a mata e a terra, enfim, sobre a natureza em que estão envoltos.

Em nossa observação centrada na escola, vimos muitas vezes as crianças brincarem de baixo do assoalho de cozinhar. Sabiam manipular, por exemplo, elementos da natureza, como barro, sementes, gravetos e folhas.

Contudo, esses saberes de experiência feito eram pouquíssimas vezes trabalhado pedagogicamente pela professora, que apresentava uma 
ênfase conteudista, reproduzindo práticas pedagógicas modernocoloniais, isto é, deixando de lado, a alteridade dos alunos, seus saberes.

Com isso, não se quer dizer que de uma perspectiva decolonial, a pedagogia passe a negligenciar os saberes mundialmente reconhecidos e sistematizados. Não, não se trata disso. Em relação ao aluno, trata-se apenas de se ter como ponto de partida a "[...] explicação do mundo de que faz parte a compreensão de sua própria presença no mundo" (FREIRE, 2002, p. 90), como ponte para outros conhecimentos, respeitando-se seus modus vivendi, considerando-se sua alteridade, como pessoa humana, tão invisibilizada pelo paradigma modernocolonial, fortemente etnocêntrico.

Pontualmente, houve uma prática pedagógica realizada pela professora, que reforçou a necessidade de se partir de uma hipótese de contexto, já mencionada anteriormente: A Semana da Criaça. Nela, a professora incorporou várias brincadeiras do cotidiano das crianças, envolvendo ludicamente tanto as crianças da educação infantil, quanto as dos anos iniciais, por meio de dinâmicas e brincadeiras.

Práticas estas que possibilitaram interagir e aprender um com o outro. Foi uma semana intensiva de atividades e brincadeiras, que dialogava com as infâncias amazônicas.

Partindo da pesquisa de Coelho (2020), as brincadeiras que mais atraíam as crianças eram que as que envolvia movimento. Uma delas foi encher um litro de garrafa pet com água do rio. As crianças organizadas em equipe escolherem um representante, e este corria da escola até o rio para encher a garrafa. Retornavam à escola com as garrafas cheias, quem chegava primeiro, vencia.

Nesse sentido, a hipótese de contexto é fundamental para o respeito à alteridade, desde o núcleo ético de qualquer grupo de sujeitos aprendentes, mas também porque promove a horizontalidade entre saberes, não no sentido assimétrico de invasão cultural (FREIRE, 1985) em que um conhecimento é inflacionado como certo, o padrão a ser seguido, enquanto que o outro é tido pejorativamente como conhecimento vulgar (GALLIANO, 1979). Nesse sentido, a hipótese de contexto serve, fundamentalmente, para ser o meio pelo qual se parte de um ponto concreto, próprio da realidade dos sujeitos em foco, mas que se direciona para a relação e aprendizagem com outros conhecimentos da cultura mundial. 
Conforme demonstra a empiria descrita na pesquisa da qual resulta esse artigo, indicamos que o brincar se traduz em um elemento de hipótese de contexto assertivo para desenvolver o processo ensinoaprendizagem com crianças, inclusive no contexto da educação escolar.

\section{3 - Valorizar Memórias Coletivas dos Movimentos de Resistência}

Como explicitado anteriormente, as memórias coletivas dos movimentos de resistência, em linhas gerais, tendem a ser base de conhecimentos de resistência e estratégias e táticas de sobrevivência ante o poderio secular do paradigma moderno-colonial.

Em nossa análise sobre Coelho (2020), os sujeitos principais não são adultos pertencentes a grupo social de algum tipo de resistência existencial-cultural, nem são pertencentes a algum movimento social institucionalizado, ou de associações, sindicatos, etc. Tratam-se de crianças que estão a cursar o pré-I, o pré-II, e o $1^{\circ}$ e $2^{\circ}$ anos do ensino fundamental, todos juntos em um único espaço educativo, tendo como medidadora do processo ensino-aprendizagem, apenas uma professora.

Mesmo assim, compreendemos que o processo educativo é permeado de memórias de luta e resistência que seus ancentrais - desde indígenas e povos ribeirinhos e mais especificamente, quilombolas - tem passado adiante no tempo presente.

Trata-se de maneiras distintas de resistir ao poderio econômico da cidade capitalista e individualista, por meio, por exemplo, de estratégias solidárias chamadas puxirum, que envolve a prática da pesca, a construção de casas, a limpeza de terras para o plantio (LIMA JR., 2019).

Nesse sentido, tais memórias de resistência são potenciais a serem trabalhadas como hipótese de contexto nas atividades pedagógicas com as crianças. Para tanto, é fundamental haver maior consciência docente e de membros da comunidade quanto à subversão do paradigma modernocolonial.

No caso da pesquisa de Coelho (2020), percebemos e a professora confirmou, a ausência da comunidade como integrante ativa do processo educativo escolar, mas também percebemos que a professora, na melhor das intenções, tende a trabalhar conteúdos curriculares sem considerar a realidade contextual dos alunos. Dados estes que prejudicam o trabalho de valorizar e fortalecer memórias de resistência. 
Não queremos dizer que o indicativo proposto por Mota Neto (2016) é desconexo para a constituição de pedagogias decolonais. Ao contrário, concordamos plenamente com tal proposição. Apenas alertamos, que as pedagogias decoloniais - como discurso praxiológicoainda está distante de se efetivar, pelo menos no caso desta pesquisa.

\section{4 - Buscar "Outras" Coordenadas Epistemológicas}

Considerando os dados da pesquisa de campo de Coelho (2020), passamo a considerar este indicativo de Mota Neto (2016) como um princípio central à construção de propostas pedagógicas decoloniais porque se de um lado, temos a ciência moderna como um dos principais pilares de sustentação da colonialidade do saber pela via da construção do conhecimento (MIGNOLO, 2014), de outro ajuda a descontruir o mito do cientifismo (DUSSEL, 1980) como conhecimento neutro, racional, metódico, capaz de mudar os condicionantes negativos da humanidade.

De nosso ponto de vista, é na circunscrição do cientificismo que a pedagogia moderno-colonial impõe sua perspectiva de educação monocultural impositiva como colonialidade e é precisamente contrária a essa perspectiva que se anuncia: é preciso decolonizar a pedagogia, tendose por parâmetro o termo "outras" em relação às coordenadas epistemológicas".

Contudo, ao analisar os dados de Coelho (2020), não notamos esse princípio se aplicado de modo consciente pela professora, desde o aporte das pedagogias decoloniais, mas como uma atividade pontual, considerando uma data comemorativa: o dia das crianças.

A despeito disso, é possível interpretar essa atividade desde o ponto de vista do pensamento decolonial como energia de descontentamento ante a violência moderno-colonial a se esprair à educação escolar. Para tanto, vejamos o excerto a seguir:

Da educação infantil, faltam muitos materiais. Como no pré I, que está iniciando, tu precisa trabalhar com jogos, mas você não tem. Não tem uma bola, não tem um brinquedo, não tem nada para ter aquele momento de recreação, para criança conhecer. Vai para as outras escolas, mas não vem para a nossa. Você tem que ir atrás. A falta de energia é outra situação, que você não pode levar um vídeo, uma música, porque não dá pra colocar. Todo tempo tem que colocar ou é pintura ou é desenho pra pintar ou ela mesma desenhar, porque não tem como levar um computador, um data-show para colocar, fazer 
uma coisa diferente com eles. Assim, fica difícil (Entrevista com a Professora) (COELHO, 2020, p. 188).

Considerando esse excerto, é possível fazer uma analogia com o modo como Mignolo apresenta materialmente a decolonialidade, isto é, como resultante da resistência e da luta contra a instalação da modernidade/colonialidade. Assim, é possível interpretar que a Semana da Criança tenha sido um ato de rebeldia ante à tanta negação e invisibilização imposta pela pedagogia moderno-colonial, imperante nos sistemas educacionais.

Nesse sentido, a Semana da Criança, realizada pela professora, para além de como abordada no item 2 "Partir de uma hipótese de contexto", pois essa Semana demonstra não apenas uma perspectiva de facilitar a aprendizagem a partir da realidade e saberes imediatos das crianças, mas também evidencia uma maneira de prática pedagógica que, contrária à normatividade curricular da pedagogia moderno-colonial, respeita a alteridade das crianças, e nem por isso deixa de abordar conhecimentos curriculares culturalmente relevantes para todo e qualquer ser humano.

Ante o exposto, buscar "outras" coordenadas epistemológicas é princípio relevante que pode se fazer presente de modo consciente em relação ao referencial teórico do paradigma decolonial, ou mesmo sem nenhuma noção deste, surgindo como energia de descontentamento, como interpretado anteriormente.

\section{5 - Afirmar-se como uma Utopia Política.}

A utopia política das pedagogias decoloniais se refere à possibilidade de uma prática pedagógica "outra”, tendo em vista a construção de um mundo melhor, solidário e intercultural, na direção da transmodernidade.

Embora a professora não tenha demonstrado do ponto de vista teórico uma aproximação com o pensamento decolonial e mais precisamente com as pedagogias decoloniais, do ponto de vista material, podemos considerar que somente propôs a Semana da Criança ante às negativas dos sistemas social e educacional, que invisibilizam a comunidade e a escola, a professora agiu de modo contrário aos ditames violentos do paradigma moderno-colonial e sua pedagogia, e, se o fez, é porque tem esperança e acredita que pode fazer uma prática pedagógica 
melhor para as crianças, acredita em um futuro melhor para as crianças. Elementos que, ao nosso ponto de vista, corroboram as pedagogias decoloniais, como meios utópicos para se alcançara um mundo "outro", transmoderno.

\section{Considerações Finais}

O artigo realizou uma análise de possíveis contribuições de práticas pedagógicas com crianças ribeirinhas na Amazônia às pedagogias decoloniais, a partir dos registros de Coelho (2020) e de algumas proposições sobre práticas pedagógicas decoloniais de Mota Neto (2016).

Para tanto, realizamos uma breve descrição existencial das crianças, pois consideramos que as crianças passam pelo triplo processo antropológico de hominização, humanização e singularização, desde o contexto ribeirinho e amazônico em que vivem. Significa dizer que as crianças, ao chegarem na escola, já levam consigo saberes de experiência feito. Em outras palavras não chegam como "tábulas rasas", como preconiza a pedagogia tradicional moderno-colonial.

Aliás, também realizamos um caracterização do ambiente de aprendizagem das crianças, em que percebemos que o trabalho da professora é pautado em grande parte pela pedagogia de matriz modernocolonial, com ênfase na alfabetização, a partir de práticas pedagógicas de cópias da lousa, leitura do alfabeto, sílabas simples e textos pequenos e de baixa complexidade linguística, além de se utilizar de desenhos livres, atividades de coordenação motora, cópias das vogais e dos números de o a 9.

No entanto, a realidade dinâmica permite espaço para o subversivo, realizado de modo consciente do ponto de vista ético-político ou simplesmente como atitude de resistência. Foi o que depreendemos ao analisar a prática da professores em diálogo com os indicativos pedagógicos, que serviram de base para a pesquisa.

Em relação à necessidade de educaras e educadores subversivos, destacamos que as pedagogias decoloniais - não como energia de descontentamento, mas como pujança intelectual - não se efetiva na prática da professora em tela, mas não significa dizer que se torna inerte ante à realidade de marginalização que se encontra em relação ao sistema social como um todo, e, especificamente em relação ao sistema educacional ao qual a escola é vinculada. Não! Mesmo com todos os 
condicionantes, realizou a Semana da Criança, como atividade pedagógica de fratura com a pedagogia moderno-colonial, dada a possibilidade de reconhecimento identitário da alteridade das crianças, a partir de suas brincadeiras locais, da interação entre elas, independentemente de faixa etária ou "classe" escolar.

Foi principalmente a partir da realização desta Semana da Criança, que percebemos, na prática pedagógica da professora a hipótese de contexto, sobretudo a partir do brincar das crianças inserido organicamente em uma prática pedagógica escolar.

Em relação à valorização de memórias coletivas, apesar dos principais sujeitos a quem é direcionado o trabalho pedagógico serem crianças, notamos que cabe a inserção de memórias quilombola, ribeirinha e indígena, como estratégias solidárias de resistência ao paradigma moderno-colonial. Contudo, não notamos nos registros de Coelho (2020) algum indicativo de que essa valorização tenha ocorrida do ponto de vista da prática pedagógica com as crianças. Reiteramos que esta ausência, não desqualifica o indicativo feito por Mota Neto (2020). Antes, reforça-o para que seja organicamente realizado visando a utopia transmoderna.

Similar é nossa análise quanto à busca de "outras" coordenadoras epistemológicas, pois não notamos esse elemento ser aplicado de modo consciente pela professora, desde os aportes das pedagogias decoloniais, mas sim na perspectiva da energia de descontentamento pedagógico, pois, ante à invisibilização, à tantas negações impretadas pelo sistema educacional, a professora, como ato de rebeldia que respeita os saberes culturais das crianças, sem deixar de abordar temas curriculares relevantes para sua formação humana, como a coordenação motora, durante as brincadeiras.

Em relação à afimação das pedagogias decoloniais como utopia política, já apresentamos que a professora não tem aproximação teórica com as pedagoias decoloniais, do ponto de vista material, isto é, analogicamente, como energia de descontentamento (tal como apontado por Mignolo, 2008), inferimos que a professora somente realizou a Semana da Criança por que acretida, tem esperança. O que implica em dizer: a professora se ancora na utopia de um mundo melhor, inclusive para as crianças. Para nós, trata-se do gérmen material da utopia política decolonial como passo a um mundo transmoderno. 
Por fim, cabe reiterar que desde o foco da tese doutoral de Mota Neto (2016), o autor deixa claro que esses cinco indicativos pedagógicos decoloniais não esgotam a temática, por isso ser pertinente a correlação feita com Coelho (2020) e inclusive com outros estudos mais. Dado que indica a pertinência para a realização de pesquisas futuras pesquisas, que visem ao fortalecimento do corpus teórico-prático das pedagogias decoloniais.

\section{Referências}

AOOD, Maria Helena; DIAS, Alder de Sousa; ABREU, Waldir Ferreira de. Decolonizar a formação de professores na Amazônia: uma possível agenda de trabalho. In: ABREU, Waldir Ferreira de; OLIVEIRA, Damião Bezerra. Pedagogias decoloniais, decolonialidade e práticas formativas na Amazônia. Curitiba: CRV, 2021. p. 161-174.

CHARLOT, Bernard. Da relação com o saber: elementos para uma teoria. Porto Alegre: Artes Médicas, 2000.

COELHO, Maria Auxiliadora dos Santos. Práticas pedagógicas de professores do multisseriado na tríplice fronteira Amazônica BrasilPeru-Colômbia: um olhar decolonial na educação ribeirinha. 2020. 203f. Dissertação (Mestrado em Educação) - Universidade Federal do Pará, Belém, 2020. Disponível em:

http://ppgedufpa.com.br/arquivos/File/mariaauxiliadora.pdf. Acesso em 14 jan. 2021.

DIAS, Alder de Sousa; ABREU, Waldir Ferreira de. Didáticas Decoloniais no Brasil: uma análise genealógica. Educação, Santa Maria, v. 45, 2020. Disponível em:

https://periodicos.ufsm.br/reveducacao/article/view/41328/html. Acesso em: 174jan. 2021.

DUSSEL, Enrique. La Pedagógica Latinoamericana. Bogotá: Editorial Nueva América, 1980.

DUSSEL, Enrique. El encubrimiento del otro: hacia El origen del mito de la modernidad. 2. ed. México: Editorial Cambio XXI, 1994.

DUSSEL, Enrique. Filosofías del Sur: descolonización y transmodernidad. Ciudad de México: AKAL, 2017. 
DUSSEL, Enrique. Siete ensayos de filosofía de la liberación: hacia una fundamentación del giro decolonial. Madrid: Editorial Trota, 2020.

FREIRE, Paulo. Extensão ou comunicação? $8^{\mathrm{a}}$ ed. São Paulo: Paz e Terra, 1985 .

FREIRE, Paulo. Política e educação. $3^{\text {a }}$ ed. São Paulo: Cortez, 1997.

FREIRE, Paulo. Pedagogia da Autonomia: saberes necessários à pratica educativa. $23^{\mathrm{a}}$ ed. São Paulo: Paz e Terra, 2002.

GALLIANO, Alfredo Guilherme. O Método Científico: teoria e prática. São Paulo-SP: HARBRA, 1979.

GOMES, Romeu. Análise e interpretação de dados de pesquisa qualitativa. In: MINAYO, Maria Cecília de Souza (org.). Pesquisa Social: teoria, método e criatividade. $34^{\mathrm{a}}$ ed. Petrópolis- RJ: Vozes, 2015. p. 79108.

LEGRAMANDI, Aline Belle; GOMES, Manuel Tavares. Insurgência e resistência no pensamento freiriano: propostas para uma pedagogia decolonial e uma educação emancipatória. Revista @mbienteeducação, São Paulo, v. 12, n. 1, p. 24-32, jan./abr. 2019. Disponível em:

http://publicacoes.unicid.edu.br/index.php/ambienteeducacao/article/ view/669. Acesso em: 17 jan. 2021.

LIMA JR., Rosivaldo Bentes. "No meu tempo nós remava lá na cabeceira para estudar lá na boca do mocambo": trabalhadores do campo e a exclusão educacional escolar - o puxirum no Mocambo do ArariParintins-AM. RECH, Humaitá, v. 4, n. 1, p. 418-434, jan./jun. 2019. Disponível em:

https://www.periodicos.ufam.edu.br/index.php/rech/article/download/ 5841/4561/. Acesso em: 17 fev. 2021.

MIGNOLO, Walter. La opción de-colonial: desprendimiento y apertura. Un manifiesto y un caso. Tabula Rasa. Bogotá - Colombia, n.8, p. 243281, jan./jun. 2008. Disponível em:

http://www.revistatabularasa.org/numero-8/mignolo1.pdf. Acesso em: 14 jan. 2021. 
MIGNOLO, Walter. Desobediência Epistémica: retórica de la modernidade, lógica de la colonialidad y gramática de la descolonialidad. Buenos Aires: Del Signo, 2014.

MINAYO, Maria Cecília de Souza (org.). Pesquisa Social: teoria, método e criatividade. $34^{\mathrm{a}}$ ed. Petrópolis- RJ: Vozes, 2015.

MOTA NETO, João Colares da. Educação Popular e Pensamento Decolonial Latino-Americano em Paulo Freire e Orlando Fals Borda. 2015. 368f. Tese (Doutorado em Educação) - Universidade Federal do Pará, Belém, 2015. Disponível em: http://repositorio.ufpa.br/jspui/handle/2011/8383 . Acesso em 14 jan. 2020.

MOTA NETO, João Colares da. Por uma Pedagogia Decolonial na América Latina: reflexões em torno do pensamento de Paulo Freire e Orlando Fals Borda. Curitiba: CRV, 2016.

OLIVEIRA, Luiz Fernandes de. Histórias da África e dos africanos na escola. As perspectivas para a formação dos professores de História quando a diferença se torna obrigatoriedade curricular. Rio de Janeiro, 2010. 281f. Tese de Doutorado - Departamento de Educação, Pontifícia Universidade Católica do Rio de Janeiro. Disponível em: http://www.dominiopublico.gov.br/download/texto/cp128102.pdf. Acesso em: 13 abr. 2020.

OLIVEIRA, Ivanilde Apoluceno de; MOTA NETO, João Colares da. A construção de categorias de análise na pesquisa em Educação. In: MARCONDES, Maria Inês; OLIVEIRA, Ivanilde Apoluceno de; TEIXEIRA, Elizabeth (org.). Abordagens teóricas e construções metodológicas na pesquisa em Educação. Belém: EDUEPA, 2011. p. 167186.

OLIVEIRA NETO, Adolfo da Costa; SOBREIRO FILHO, José. Aprendizagem territorial na Amazônia ribeirinha: primeiras aproximações. In: SOUZA, Dayana Viviany Silva; VASCONCELOS, Maria Eliane de Oliveira; HAGE, Salomão Antônio Mufarrej (org.). Povos Ribeirinhos da Amazônia: educação e pesquisa em diálogo. Curitiba: CRV, 2017. p. 147-164.

PALERMO, Zulma. Para una Pedagogía Decolonial. Buenos Aires: Del Signo, 2014. 
WALSH, Catherine. Interculturalidade Crítica e Pedagogia Decolonial: insurgir, re-existir e re-viver. In: CANDAU, Vera Maria Ferrão (org.). Educação Intercultural na América Latina: entre concepções, tensões e propostas. Rio de Janeiro: 7 Letras, 2009. p. 12-42.

WALSH, Catherine; OLIVEIRA, Luiz Fernandes de; CANDAU, Vera Maria Ferrão. Colonialidade e pedagogia decolonial: Para pensar uma educação outra. Arquivos Analíticos de Políticas Educativas, v, 26, n. 83, p. 1-11, 2018. Disponível em: http://dx.doi.org/10.14507/epaa.26.3874. Acesso em: 17 jan. 2021. 


\section{Possibilities for decolonial pedagogies based on educational practices with riverside children in the Amazon}

RESUMEN/ABSTRACT: The present article, on the theme of decolonial pedagogies, brings pedagogical practices with children as specificity, carried out in the Amazonian and riverside context. It has the following problem-question: what contributions to decolonial pedagogies can come from pedagogical practices with riverside children in the Amazon? In this sense, it aims to analyze possible contributions of pedagogical practices with riverside children in the Amazon to decolonial pedagogies. Methodologically, it is a bibliographic research, with a qualitative approach, anchored in some references, such as Coelho (2020), Mota Neto (2016), Dussel (1980; 1994; 2017; 2020), Mignolo (2008; 2014), among others, and which relied on elements of content analysis as a technique of systematization and data analysis. Among the results and conclusions, it is clear that decolonial pedagogies, as intellectual strength, are not yet organically assumed by teachers in general, but as discontent energy, they are present to operate epistemic fractures to modern-colonial pedagogy.

Palabras Clave/Keywords: Decolonial pedagogies. Pedagogical practices. Riverside child. Amazon.

Alder de Sousa Dias

Doutorando em Educação pela Universidade Federal do Pará (UFPA), Mestre em Educação pela Universidade do Estado do Pará (UEPA), Especialista em Filosofia da Educação (UFPA) e Graduado em Pedagogia pela UEPA. Professor da Universidade Federal do Amapá (Unifap) - Campus Mazagão. Pesquisador do Grupo de Estudos e Pesquisas em Educação, Infância e Filosofia (GEPEIF/UFPA/CNPq), Amazônia Sustentável (Unifap/CNPq) e da Rede de Pedagogias Decoloniais na Amazônia (RPPDA). E-mail: auxiliadoracoelho@ufam.edu.br Orcid: https://orcid.org/oooo-0oo3-1470-8774

Waldir Ferreira de Abreu Pós-Doutor em Ciências da Educação - Espanha (2013), Doutor em Ciências Humanas: Educação pela PUC-Rio (2010). Professor adjunto IV do Curso de Licenciatura em Pedagogia da UFPA e do Programa de Pós-Graduação em Educação (PPGED)/ICED-UFPA. Líder do Grupo de Estudos e Pesquisas em Educação, Infância e Fïlosofia (GEPEIF/UFPA/CNPq).

E-mail: awaldir@ufpa.br

Orcid: https://orcid.org/oooo-0oo2-0245-9072

Recebido em: 20/o3/2021 Aprovado em: 05/05/2021 